\title{
A PERSPECTIVA DO PROFESSOR NA EDUCAÇÃO AMBIENTAL
}

\author{
Rosangela Inês Matos Uhmann ${ }^{1}$ \\ Luciane Follmann²
}

\begin{abstract}
RESUMO
O presente artigo aborda algumas concepções e práticas pedagógicas sobre a Educação Ambiental (EA) discutidos num processo de formação continuada entre licenciandos, formadores e professores de escola. Os dados aqui apresentados foram construídos mediante análise dos discursos entre os participantes de um dos encontros dos Ciclos Formativos em Ensino de Ciências, o qual tratou das "Questões controversas em uma perspectiva crítica da Educação Ambiental que podem ser abordadas em sala de aula". Além dos aspectos documentais no estudo das leis ambientais foi indicado o uso de imagens (cartum) para trabalhar com as questões socioambientais em discussão de forma controversa na Educação Básica. É na formação continuada, portanto, a exemplo dos encontros formativos, que se percebe a problemática no desenvolvimento das ações de EA, tema controverso emergente e urgente, o que exige iniciativas de participação, conhecimento e responsabilidade principalmente entre os sujeitos escolares de forma contínua, integrada e adequada à preservação do nosso ambiente.
\end{abstract}

Palavras-chave: Questão socioambiental. Estratégias de ensino. Formação docente. Encontro formativo.

\section{PERSPECTIVE OF TEACHERS IN ENVIRONMENTAL EDUCATION}

\begin{abstract}
The present article approaches some concepts and pedagogical practice about Environmental Education (EE) discussed in a process of continuous training between graduating, trainers and a school teachers. The presented datas were built through analysis of speeches the participants of one meeting of Formation Circles in Science Teaching, which dealt with: "Controversial issues in a critical perspective of Environmental Education that can be approached in classroom". Besides the documental aspects in the study of Environmental Laws, were also indicated the use of images (cartom to work with socioenvironmental issues in discussion in controversial way in Basic Education. However, the continued formation, wich example from the formation meetings we can perceived the problematic in the development of the actions in $\mathrm{EE}$, controversial theme emergent and urgent, that need initiative of participation, knowing and responsibilities mainly between the school sujects in continuous way, integrated and adequate to the preservation of our environment.
\end{abstract}

Keywords: Socioenvironmental issues. Teaching strategies. Teachers training. Formative meetings.

RECEBIDO EM: 25/2/2018

ACEITO EM: 18/3/2019

\footnotetext{
${ }^{1}$ Professora de Estágio Curricular Supervisionado e Prática de Ensino do curso de Química Licenciatura da Universidade Federal da Fronteira Sul - UFFS - Campus Cerro Largo, RS. Doutorado e Mestrado em Educação nas Ciências pela Unijuí. Graduação em Ciências no Ensino Fundamental e Química no Ensino Médio na Unijuí. Especialização em Educação Química pela Unijuí, ljuí, RS. Membro do Grupo de Estudos e Pesquisa em Ensino de Ciências e Matemática - Gepeciem (UFFS). Coordenadora Pibid Química/Capes. rosangela.uhmann@uffs.edu.br dos e Pesquisa em Ensino de Ciências e Matemática (Gepeciem) da UFFS. lucianefollmann@yahoo.com.br
} 
A Educação Ambiental (EA) atualmente tem papel fundamental para alavancar a conscientização e sensibilização de que o ser humano é parte integrante do meio ambiente, tentando assim superar a visão antropocêntrica do homem em relação à natureza. Nesse sentido, cabe destacar, conforme Lei $N^{\circ}$ 9.795, de 27 de abril de 1999, a EA como um "[...] componente essencial e permanente da educação nacional, devendo estar presente, de forma articulada, em todos os níveis e modalidades do processo educativo, em caráter formal e não-formal" (BRASIL, 1999, p. 1). Neste sentido, urge a necessidade de melhorarmos nossas ações, estabelecendo limites de consumo. Isso envolve não só os consumidores, mas também as empresas que precisam desenvolver produtos ecologicamente corretos, com materiais que não agridem o ambiente. Para tanto, a escola é local para abordar esse tema, não se restringindo a esse espaço, mas que tal entendimento das questões ambientais seja problematizado associando o cotidiano dos alunos ao meio ambiente em que vivemos.

Com o objetivo de identificar as concepções e práticas pedagógicas referentes à EA até então desenvolvidas por alguns professores formadores e licenciandos da Universidade Federal da Fronteira Sul (UFFS), Campus Cerro Largo, assim como dos professores de Ciências, Matemática, Biologia, Física e Química (das redes particular, municipal e estadual de ensino) da Região Noroeste do Rio Grande do Sul, realizamos esta pesquisa qualitativa por meio da análise das falas de tais participantes, as quais foram gravadas durante um dos encontros dos Ciclos Formativos em Ensino de Ciências.

Acreditamos ser pertinente trabalhar questões sobre a EA em contexto formativo para que tais aspectos sejam levados ao ambiente escolar desde as séries iniciais, considerando que esse é muitas vezes o primeiro ou o único local no qual alguns indivíduos precisam ser instigados para sua significação conceitual. Até porque, segundo Güllich (2013, p. 317): "Conteúdos atuais, polêmicos e de interesses sociais, tais como sexualidade, uso de drogas, preservação do ambiente, na maioria das vezes pouco aparecem nos LD, embora os PCNs apontem esses temas como pertinentes e transversais para todo o ensino". Enfatizamos assim a importância do estudo e pesquisa no acesso às informações e difusão da discussão sobre a problemática ambiental.

Ao abordar a temática da EA em âmbito escolar é fato que surgirão questionamentos a respeito das leis entre outros documentos a respeito da EA. Neste sentido: "Cada professor, dentro da especificidade de sua área, deve adequar o tratamento dos conteúdos para contemplar o Tema Meio Ambiente, assim como os demais Temas Transversais" (BRASIL, 1997, p. 27). Para tanto, é essencial que a equipe de gestão das escolas consiga orientar seus professores a trabalharem a temática da EA utilizando diferentes modalidades didáticas, proporcionando uma visão ampla sobre as questões culturais e socioambientais, como sugerem os Parâmetros Curriculares Nacionais (PCNs): meio ambiente e saúde (BRASIL, 1997). Justificamos assim a importância de trabalhar com o tema da EA na formação de professores em um dos encontros dos Ciclos Formativos em Ensino de Ciências na UFFS. Para tanto, após a metodologia, problematizaremos a temática da EA e, consequentemente, a reflexão sobre o diálogo entre os participantes proporcionado no encontro formativo. 


\section{METODOLOGIA}

Esta pesquisa constituiu seu corpus em um dos encontros de formação continuada por meio do Projeto de Extensão: Ciclos Formativos em Ensino de Ciências, que está sendo realizado na Universidade Federal da Fronteira Sul (UFFS), Campus Cerro Largo, RS desde 2011. Sendo assim, por meio do Projeto de Extensão são proporcionados encontros mensais sistemáticos de tempo/espaço de formação inicial e continuada dos quais participam não só professores da Educação Básica e professores da Universidade, mas principalmente os licenciandos dos cursos de Ciências Biológicas, Química e Física da UFFS, projeto este vinculado ao Grupo de Estudos e Pesquisa em Ensino de Ciências e Matemática (Gepeciem). Durante um dos encontros dos Ciclos Formativos em Ensino de Ciências foi debatido o tema "Questões controversas em uma perspectiva crítica da Educação Ambiental que podem ser abordadas em sala de aula", o qual foi gravado. Fizeram parte do encontro 44 licenciandos dos cursos de Ciências Biológicas, Química e Física, 12 professores formadores da UFFS e 47 professores de Ciências, Matemática, Biologia, Física e Química da Educação Básica das escolas próximas da UFFS, assim como de outras cidades da Região Noroeste do RS, das redes municipal, estadual e particular de ensino.

Para esta pesquisa de abordagem qualitativa existem formas variadas de registrar as observações, entre as quais "[...] a gravação tem a vantagem de registrar todas as expressões orais" segundo Lüdke e André (2011, p. 37), constituindo oportunidade de analisar minuciosamente as falas dos participantes dos encontros, ressaltando-se que, para descrever as falas, foi necessário ouvir várias vezes a gravação para entender a riqueza dos detalhes das falas, ou seja, dos discursos. Conforme Lüdke e André (2011, p. 38), "[...] a análise documental pode se constituir numa técnica valiosa de abordagem de dados qualitativos". Destaca-se que os participantes assinaram o Termo de Consentimento Livre e Esclarecido assegurando o anonimato, nomeados de Formador A, Formador B para professores da universidade, Docente A, Docente B para professores das escolas e Licenciando A, Licenciando B para estudantes dos cursos de Licenciatura da UFFS, sucessivamente.

Também foi discutido com destaque o resgate histórico sobre a EA durante o encontro, relatado na sequência, assim como na segunda parte apresentamos uma análise das falas referente ao compartilhamento das experiências vivenciadas com a EA nas aulas, bem como a problematização de uma atividade com o uso de cartuns a respeito da EA.

\section{A EDUCAÇÃO AMBIENTAL NA FORMAÇÃO DE PROFESSORES}

No referido encontro formativo iniciamos um estudo bibliográfico sobre documentos relacionados à EA, ou seja, observamos com destaque o resgate histórico documental, referente à preocupação de alguns segmentos da sociedade civil organizada, bem como entidades governamentais que tratam de questões ambientais, como a Agenda 21, a Declaração de Tbilisi, a Declaração de Estocolmo, os PCNs do Meio Ambiente, a Lei Federal 9.795/1999, além de alguns referenciais. 
A EA é um tema para ser instigado em escolas, empresas, universidades, bem como em repartições públicas, por órgãos do governo e/ou entidades ligadas ao meio ambiente. Conforme Jacobi (2003, p. 8), "A educação ambiental propicia o aumento de conhecimentos, mudança de valores e aperfeiçoamento de habilidades, condições básicas para estimular maior integração e harmonia dos indivíduos com o meio ambiente". A temática da EA ao longo de sua história está vinculada a diferentes valores e interesses. Segundo Jacobi (2003, p. 8), a EA “[...] aponta para propostas pedagógicas centradas na conscientização, mudança de comportamento, desenvolvimento de competência, capacidade de avaliação e participação de educandos".

Cabe ao docente enfatizar a EA nas dimensões sociais, culturais, econômicas e políticas para que o aluno reflita ao: “[...] a questão não é somente conhecer para se ter consciência de algo, mas conhecer inserido no mundo para que se tenha consciência crítica do conjunto de relações que condicionam certas práticas culturais e, nesse movimento, superarmo-nos e às próprias condições inicialmente configuradas" (LOUREIRO, 2007, p. 70). Desta forma, consideramos pertinente que os docentes façam uma problematização da realidade, das atitudes e práticas desenvolvidas nas aulas, visto que ao abordar a temática da EA é possível contribuir para a formação de cidadãos críticos e responsáveis com as ações socioantrópicas e ambientais, constituindo um dos temas transversais relevantes a ser tratado em contexto educativo, assim como no encontro formativo aqui relatado.

É preciso compreender que todos nós somos parte do ambiente, e que por meio de nossas ações somos agentes modificadores de preservação e/ou de agressão. Nesse sentido, a formação de professores com base na temática da EA também investe no resgate histórico-documental com foco na EA referente à preocupação de alguns segmentos da escola e sociedade, bem como das entidades governamentais, questões atuais do dia a dia dos alunos, assim como aqueles divulgados pela mídia referente à EA.

Os problemas ambientais são globais/locais característicos do processo de globalização industrial. Por isso, na escola é preciso conhecer e incentivar o estudo permanente sobre os cuidados para preservação do ambiente, principalmente nas aulas de física, química e biologia, perante atitudes e ações sistematizadas e capazes de propiciar conhecimentos e práticas transformadoras (UHMANN; ZANON, 2012, p. 12).

Diante do exposto, é importante uma fundamentação teórica para apropriação do conhecimento das questões relacionadas à EA de forma ampla, tendo em vista as questões controversas no embate entre os ambientalistas e os meteorologistas, por exemplo, em relação ao aquecimento global e efeito estufa. O entendimento de alguns documentos que tratam da EA ajuda na compreensão, por exemplo, a Declaração de Estocolmo, que atenta para a “[...] necessidade de estabelecer uma visão global e princípios comuns que sirvam de inspiração e orientação à humanidade para a preservação e melhoria do ambiente humano" $(1972$, p. 1). É neste período que surge o paradigma teórico da ecologia política e a proliferação dos movimentos da ecologia.

A Declaração de Estocolmo visa a defender o meio ambiente para a presente e as futuras gerações. Este documento possui 26 princípios, um deles expressando: " $O$ homem tem direito fundamental à liberdade, à igualdade e ao desfrute de condições de 
vida adequadas, em um meio ambiente de qualidade tal que lhe permita levar uma vida digna, gozar de bem-estar; e é portador da obrigação de proteger o meio ambiente" (1972, p. 1).

Outra referência é a Conferência Intergovernamental de Tbilisi de 1977, considerado um dos principais eventos relacionados à EA. Durante a Conferência foram estabelecidos alguns objetivos, como:

a) favorecer a compreensão e preocupação da interdependência econômica, social, política e ecológica nas áreas rurais e urbanas; b) oferecer a todas as pessoas a oportunidade de adquirir os conhecimentos, valores, atitudes, compromissos e capacidades necessárias para proteger e melhorar o meio ambiente; c) criar normas de conduta em indivíduos e grupos e na sociedade em geral, em relação ao meio ambiente (p. 11).

No Brasil, em 27 de abril de 1999, a EA foi instituída por meio da Lei no 9.795, determinando que "[...] o indivíduo e a coletividade constroem valores sociais, conhecimentos, habilidades, atitudes e competências voltadas para a conservação do meio ambiente, bem de uso comum do povo, essencial à sadia qualidade de vida e a sua sustentabilidade" (BRASIL, 1999, p. 1). Com os avanços científicos e tecnológicos que o homem conquistou, no entanto, observa-se um aumento na utilização, exploração e destruição do meio ambiente. Neste caso, como efetivar a sustentabilidade? O que exige pensarmos que as respostas não são simples, pois a temática da EA é extremamente complexa.

De acordo com Loureiro (2006), pensar de forma complexa implica uma ação consciente, no sentido de saber o alcance de determinada ação, apresentando coerência entre o que se quer, o conhecimento dos sujeitos, a base teórica da qual se parte, onde se quer chegar e quem se beneficia com o processo desenvolvido. Em virtude disso, necessitamos repensar algumas atitudes desenvolvidas pelo homem, refletir sobre elas e investir em ações de mudanças individuais e coletivas. A abordagem da EA é um tema transversal que precisa ser abordado nas escolas em todos os níveis, indicado desde 1998 pelos PCNs do Meio Ambiente.

A questão ambiental impõe às sociedades a busca de novas formas de pensar e agir, individual e coletivamente, de novos caminhos e modelos de produção de bens, para suprir necessidades humanas, e relações sociais que não perpetuem tantas desigualdades e exclusão social, e, ao mesmo tempo, que garantam a sustentabilidade ecológica. Isso implica um novo universo de valores no qual a educação tem um importante papel a desempenhar (BRASIL, 1998, p. 180).

O desafio está em promover formas de organizar, disponibilizar e divulgar as informações da EA de modo integrado, coerente e acessível a todos, principalmente dos professores que têm nas mãos a oportunidade de dialogar com seus pares, alunos e sociedade em geral. Acreditamos ser pertinente mais estudo e pesquisa sobre EA junto a um grupo de professores em formação, tendo em vista as práticas de ensino e as suas futuras ações. A EA precisa estar presente em todos os níveis educacionais, com o objetivo de atingir todos os sujeitos nestes espaços. Conforme a Lei no 9.795: "A dimensão ambiental deve constar dos currículos de formação de professores, em todos os níveis 
e em todas as disciplinas" (BRASIL, 1999, p. 1). Nesse sentido, os professores precisam desenvolver projetos ambientais no trabalho com os conceitos científicos com um olhar de preservação aos recursos naturais.

A Conferência de Tbilisi recomenda "[...] elaborar os métodos que permitam a melhor assimilação dos conceitos, valores e atitudes idôneas em relação à temática ambiental", constituindo um dos princípios para a superação da fragmentação conceitual das relações ecológicas. "Entende-se por educação ambiental na educação escolar a desenvolvida no âmbito dos currículos das instituições de ensino públicas e privadas, englobando: educação básica; educação superior; educação especial; educação profissional e educação de jovens e adultos" (BRASIL, 1999, p. 1). Introduzir no sistema educativo abordagens direcionadas à EA de forma crítica requer considerar, também, os PCNs, que têm por princípio articular a EA nas práticas escolares/sociais.

As situações de ensino devem se organizar de forma a proporcionar oportunidades para que o aluno possa utilizar o conhecimento sobre o meio ambiente para compreender a sua realidade e atuar sobre ela. O exercício da participação em diferentes instâncias (desde atividades dentro da própria escola, até movimentos mais amplos referentes a problemas da comunidade) é também fundamental para que os alunos possam contextualizar o que foi aprendido (BRASIL, 1997, p. 48).

Considerar a EA em uma perspectiva crítica e de transformação é possível ao investigar o ambiente, as diferentes concepções e práticas educativas desenvolvidas pelos sujeitos escolares em diferentes contextos, visto que, "[...] a educação ambiental será desenvolvida como uma prática educativa integrada, contínua e permanente em todos os níveis e modalidades do ensino formal" (BRASIL, 1999, p. 1), uma vez que a reflexão e a conscientização a respeito de nossas ações quanto às questões ambientais precisam cada vez mais ser discutidas em ambiente escolar. Segundo Nóvoa (1992, p. 14): "A troca de experiências e a partilha de saberes consolidam espaços de formação mútua, nos quais cada professor é chamado a desempenhar, simultaneamente, o papel de formador e de formando". É por isso que acreditamos na importância da formação continuada por meio de encontros formativos sistemáticos, em que dialogam licenciandos, docentes da universidade e das escolas, compartilhando experiências e aprendendo juntos.

Efetivar a EA nas escolas não é tarefa fácil, pois inicialmente exige a tomada de consciência dos indivíduos (professores e estudantes) referente às relações com o ambiente, implicando a mudança de hábitos, requerendo atitudes de sustentabilidade. $\mathrm{Na}$ concepção de Reis $(2007$, p. 3), "[...] a preparação dos alunos para a participação em processos avaliativos e decisórios sobre controvérsias socioambientais ou sociocientíficas não é uma tarefa simples". "Importa valorizar paradigmas de formação que promovam a preparação de professores reflexivos, que assumam a responsabilidade do seu próprio desenvolvimento profissional e que participem como protagonistas na implementação das políticas educativas" (NÓVOA, 1992, p. 16), o que se revela um desafio aos professores no ensino da EA em contexto escolar. 
O prazer de ser educador ambiental reside não na certeza dos resultados, mas na construção permanente de novas possibilidades e reflexões que garantam o aprendizado, o respeito às múltiplas formas de vida e ao planeta e a esperança de que podemos, sim, construir um mundo melhor para todos, igualitário, culturalmente diverso e ecologicamente viável (LOUREIRO, 2007, p. 72).

Cabe ao educador introduzir e potencializar em suas aulas questões relacionadas à EA, mesmo não garantindo que os objetivos sejam alcançados, no entanto as intenções precisam ir sendo efetivadas na mediação do conhecimento junto aos alunos, para que estes sejam críticos e reflitam mais sobre as implicações das ações humanas na natureza. Para Uhmann e Zanon (2012, p. 13), “[...] construir significados referentes ao conteúdo escolar, na interação social frente aos problemas socioambientais, mobiliza e propicia condições para que todos possam pensar e aprender sobre as transformações naturais e impostas pelo ser humano". Desta forma, possibilita pensarmos o espaço escolar como um ambiente em que é possível articular os conteúdos com as questões ambientais do passado e presente e as prováveis consequências para o futuro.

Consequentemente, ensinar e aprender Ciências, por exemplo, abordando a EA segundo os PCNs: "[...] pode ser amplamente trabalhado, quanto mais se diversificarem e intensificarem a pesquisa de conhecimentos e a construção do caminho coletivo de trabalho, se possível, com interações diversas dentro da escola e desta com outros setores da sociedade" (BRASIL, 1998, p. 192), o que foi reforçado em 2012 com a aprovação das Diretrizes Curriculares Nacionais de Educação Ambiental pelo Conselho Nacional de Educação, as quais estimulam a reflexão crítica e propositiva da EA, além de nortear os cursos de formação inicial e continuada dos profissionais da educação.

Conforme Loureiro (2007, p. 70), “[...] expandir conhecimentos e a percepção do ambiente é necessário à condição de realização humana, contudo, no processo educativo isso se vincula a contextos específicos, a organizações sociais historicamente formadas", para o que consideramos pertinente uma abordagem histórica a respeito da EA. Assim, professores em formação inicial e continuada vão tendo a oportunidade de conhecer, relembrar e compartilhar documentos, concepções e práticas que tratam de questões referentes à EA.

Enfim, a "[...] formação ambiental exige um redimensionamento das práticas pedagógicas de outras diretrizes para um saber ambiental que não é apenas livresco, mas articulado com a prática social e com a estreita relação entre investigação, ensino, difusão e extensão do conhecimento" (TRISTÃO, 2004, p. 70), momentos em que o docente dialoga a respeito das diferentes estratégias de ensino proporcionadas nos encontros dos ciclos formativos, por exemplo, na forma de um debate sobre a EA, possibilitando a troca de saberes, vivências e experiências entre os participantes (professores em formação inicial e continuada) em discussão a seguir.

\section{EDUCAÇÃO AMBIENTAL EM DISCUSSÃO NA FORMAÇÃO DE PROFESSORES}

Mesmo considerando a EA de forma institucionalizada (por meio de leis, documentos...) com elementos necessários para alavancar uma discussão de forma crítica e construtiva, ainda é reduzida a sua inserção nas instituições de ensino. Embora seja consenso a necessidade da introdução da EA, ainda são poucas as ações efetivas. Diante 
dessa preocupação o tema de um dos encontros dos ciclos formativos foi organizado, que teve por objetivo analisar concepções e práticas pedagógicas de EA (em âmbito educacional) relatadas pelos professores em processo de formação inicial e continuada. $\mathrm{Na}$ fala do Formador A, o desenvolvimento de uma aula apresenta alguns momentos:

Uma proposta que desenvolvi no Ensino de Ciências foi a sugestão da coleta seletiva das pilhas, levada também ao poder púbico municipal. Pensando também na maneira de significar alguns conteúdos de Ciências, para que os alunos entendessem que é preciso e o porquê de realizar a coleta não colocando as mesmas no lixo comum. Desta forma, foram abordados a composição química das pilhas, assim como a importância de realizar o reaproveitamento destes materiais, desde que fundamentados os conceitos (FORMADOR A).

Reiteramos a importância para o desenvolvimento de propostas diferenciadas no ensino, a exemplo da coleta seletiva das pilhas, esta que foi desenvolvida no contexto da escola básica, assim relatada no processo de formação continuada. Melhor quando as ações são relacionadas ao cotidiano dos alunos, que além de contribuírem no cuidado do meio ambiente, podem auxiliar na discussão de diversos conceitos escolares abordados em ambiente escolar.

Para Cavalcanti (2013, p. 73), "A EA deve estar presente em todos os níveis da educação nacional, no sentido de promover um complemento essencial na formação de uma nova consciência humana e de seus deveres e responsabilidades socioambientais". É essencial que a formação acadêmica profissional contemple as questões atuais de cuidado ambiental, pois assim os docentes podem contribuir na formação dos alunos, uma vez que os problemas contemporâneos requerem conhecimento e práticas diferenciadas, fugindo do tradicional uso do livro didático apenas.

Como bem sabemos, as questões ambientais não precisam ser abordadas em ambiente escolar somente em datas comemorativas, como do Meio Ambiente em junho, cabendo enfatizar a relação conceitual ao das questões ambientais nas aulas de Ciências, Biologia, Física e Química, como nas demais áreas de saber. "A EA é uma educação que tem por finalidade trabalhar as questões ambientais de forma local e global, devendo estar ligada a todas as disciplinas do ensino básico" (CAVALCANTI, 2013, p. 79). Intervenções diversas precisam ser exploradas e desenvolvidas no ensino de Ciências, por exemplo,

[...] o desenvolvimento e acompanhamento de projetos de horta comunitária, triIhas ecológicas, plantio de árvores, recuperação de nascentes, racionamento de água e eletricidade, mobilização da comunidade escolar por atividades de conscientização da população sobre as questões ambientais, realização de campanhas utilizando os meios de comunicação de imprensa falada e escrita, TV e Internet sobre a problemática ambiental e assim por diante (FORMADOR A).

São atividades que podem e devem ser desenvolvidas de maneira interdisciplinar numa perspectiva crítica e não exclusivamente nas aulas de Ciências. É fundamental que as reflexões façam parte do contexto social e escolar, visto que tal espaço é propulsor na constituição do sujeito, notadamente quando a mídia tem influenciado constantemente no dia a dia das pessoas, o que nos instiga a trabalhar com os aspectos controversos de fundamental importância na atualidade, ou seja, 
[...] a discussão destas questões controversas na sala de aula justifica-se não só pelos conhecimentos que promove acerca dos conteúdos, dos processos e da natureza da ciência e da tecnologia, mas também pelas potencialidades educativas deste tipo de interação no desenvolvimento cognitivo, social, político, moral e ético dos alunos (REIS, 2007, p. 4).

O desencadeamento da discussão na perspectiva da EA desafia os docentes a refletirem sobre suas práticas junto aos licenciandos, que vão formando opiniões sobre o tema para "[...] compreender as múltiplas e complexas relações que envolvem o meio ambiente, através de programas educativos estimulando e fortalecendo uma consciência crítica dos problemas ambientais sendo responsabilidade de todos" (CAVALCANTI, 2013 , p. 74). Opiniões sobre as questões ambientais tendem a se ampliar quando pensamos criticamente sobre nossas próprias ações.

A gente tem um problema de paradigma de não repensar o modo de produção? Por que não repensar o modo de distribuição? De onde vêm a laranja, a maçã, a banana que eu consumo? Eu preciso consumir a maçã, a banana o ano inteiro? Eu posso consumir frutas da época, consumindo outras frutas e não sempre as mesmas, eu sei que é complicado e problemático, mas se a gente não tentar mudar e não abrir mão de algumas coisas a gente não consegue mudar nunca (DOCENTE A).

Como podemos perceber, existe uma preocupação com nossas ações relacionadas ao consumo diário de alguns produtos, lembrado por Docente A como um dos exemplos. É importante pensar nas alternativas, as mais viáveis para um consumo consciente, afastando os produtos industrializados em alguns momentos, assim como os que estão fora de época. No encontro formativo os participantes se pronunciaram manifestando a importância no desenvolvimento das atividades socioambientais intrínsecas à significação conceitual das ações desenvolvidas nas escolas que precisam ser compartilhadas.

Me chamou muito atenção o que essa semana a mídia divulgou. De 10 mil plantas que nós humanos já usávamos na nossa alimentação, atualmente estamos utilizando apenas 170. E depois de uma campanha os alunos começaram a trazer algumas sementes que os pais em feiras haviam pegado por curiosidade, mas não plantaram. Estamos esperando a época das favas para serem plantadas algumas das sementes que foram enviadas (DOCENTE B).

Ao abordamos a EA precisamos saber das discussões trazidas pela mídia e sociedade em geral, pois a escola integra o mundo cultural entrelaçada ao que acontece no mundo em que vivemos. Segundo os PCNs (BRASIL, 1997, p. 25), “[...] é importante que o professor trabalhe com o objetivo de desenvolver nos alunos, uma postura crítica diante da realidade, de informações e valores veiculados pela mídia e daqueles trazidos de casa". Desta forma percebemos que o Docente B trouxe para o contexto escolar informações a respeito da realização da coleta e plantio de sementes, constituindo cuidado com a flora. Pensar como Tristão (2004, p. 121) é entender o “[...] processo de aprendizagem para além da escola, ou seja, nos múltiplos contextos espaços/tempos vividos". Infelizmente, a devastação da flora é devida à influência da ação do homem na natureza, no entanto o Docente B partiu de informações divulgadas pela mídia, de- 
senvolvendo atividades com os alunos de conscientização com relação à preservação de algumas sementes. A questão que aflora é a autoconsciência, essa que requer mais elementos, um dos quais é pensar sobre nossas ações e atitudes:

[...] apesar das ações ou mesmo tendo ações ambientais, eu acho que o diferencial é fazer pensar, porque se o sujeito só praticar a ação e não pensar profundamente sobre o que ele está fazendo ele também não reconstrói a vida dele. [...] Como eu encaminho a minha aula, se a minha aula é investigativa ela leva à pesquisa, ela leva ao questionamento, à reconstrução de práticas, à escrita reconstrutiva e então produzir conceito ao trabalhar no ensino de Ciências (FORMADOR B).

Percebemos que o Formador B destaca a importância de as ações serem desenvolvidas com reflexão por parte dos alunos e professores. É fato: "A formação deve estimular uma perspectiva crítico-reflexiva, que forneça aos professores os meios de um pensamento autônomo e que facilite as dinâmicas de auto-formação participativa" (NÓVOA, 1992, p. 13). Como discutido: "É importante a ação desde que consiga significar aquele conteúdo aos sujeitos participantes do trabalho" (FORMADOR A), contribuindo para que eles construam o conhecimento, confrontando diferentes valores, ideias, concepções e práticas, pois,

[...] na medida em que a EA faça parte do contexto escolar em cada área de saber, os estudantes passam a ter conhecimentos associados com atitudes de preservar e fiscalizar ambientes, recursos hídricos (águas), solo, atmosfera, com escoIhas responsáveis tanto em relação ao consumo, quanto no descarte de materiais, com cuidado permanente frente às formas de poluição e degradação ambiental (UHMANN, 2011, p. 111).

O discurso pedagógico acontece quando o professor traz os conceitos por meio da mediação, fazendo-se necessário tomar consciência do discurso usado em sala de aula. "O processo do ensino é uma atividade de mediação pela qual são providas as condições e os meios para os alunos se tornarem sujeitos ativos na assimilação de conhecimento" (LIBÂNEO, 1994, p. 89), ou seja, cabe ao docente fazer a mediação junto aos alunos com relação às questões ambientais, conceituais e atitudinais.

Para contribuir no processo de ensino e aprendizagem a universidade deve possibilitar e favorecer a formação de cidadãos responsáveis e comprometidos social e politicamente com a construção de sociedades sustentáveis. É neste sentido que os encontros dos ciclos formativos fazem a diferença devido à preocupação com o ensino e a educação. A começar pelo compartilhamento de experiências vivenciadas em sala de aula, e também de reflexões sobre as práticas desenvolvidas e relatadas pelos professores em relação às questões controversas em uma perspectiva crítica da EA. Para tanto "É preciso constituir espaços de discussão teórico-prática, em que se efetivem as vivências necessárias para a formação de uma nova consciência sobre como a humanidade precisa relacionar-se com o ambiente" (SCHULZ et al., 2012, p. 7). Nesta perspectiva, consideramos essencial, desde a iniciação à docência e com extensão na formação continuada, que sejam debatidas principalmente as questões socioambientais, visto ser uma questão controversa e complexa, uma vez que o ser humano precisa ter consciência de que suas ações influenciam no meio ambiente. 
Tratar de um tema para promover um olhar crítico na escola é a questão controversa, não é simples, porque nós professores da área das Ciências Naturais temos enraizada uma educação linear, tradicional, na qual nós nos formamos, onde a Educação Ambiental era uma informação, nós tínhamos sim que aprender a reciclar, separar, saber que agrotóxicos faziam mal. E o que a professora $X$ traz hoje aqui é uma análise diferente. De desmistificar estas nossas visões simplistas da área das ciências e proporcionar ao aluno em sala de aula temas que, sim, tragam ganchos aos nossos conteúdos [...] Emerge aqui para nós o quanto interdisciplinar é o tema levado à sala de aula (FORMADOR C).

Ao olharmos sob a ótica das questões controversas faz-se necessário conhecermos e compreendermos o contexto social e cultural, possibilitando avanços nas práticas de questões ambientais, por exemplo. Ainda que sejam inegáveis as influências da escola sobre a sociedade, sabemos que não se modifica a sociedade influenciada unicamente pela escola. Isso, porém, não diminui nossa responsabilidade de mudar a história de uma cultura da continuidade normatizada das ações para a criticidade na reconstrução de práticas sustentáveis.

Com o objetivo de disponibilizar alguns subsídios que possam ser usados em sala de aula para trabalhar com os alunos, um tema controverso, por exemplo, no encontro dos ciclos formativos foram apresentados alguns cartuns referenciados da Internet. A sugestão foi que os participantes em grupos analisassem um cartum respondendo dialogicamente a alguns questionamentos. Após as reflexões, foi socializado de forma conjunta e partilhado o que foi discutido no pequeno grupo. Segundo Reis (2007, p. 8), "[...] atividades de discussão em pequeno grupo contribuem positivamente para os processos de argumentação e de reflexão, constituindo uma experiência agradável e significativa em termos de aprendizagem".

Com essa possibilidade, acreditamos ser possível analisar as ideias dos alunos em relação à EA, usando, por exemplo, estratégias como dos cartuns de forma crítica. Assim como este recurso, outras potencialidades podem ser trabalhadas, buscando compreender ao analisar as inter-relações que existem entre o discurso e a prática, ouvindo todos os sujeitos escolares.

Docentes e licenciandos foram instigados a refletir sobre um cartum a partir dos questionamentos: Qual é a questão controversa observada na análise do cartum? É possível observar diferentes pontos de vista? Qual a mensagem apresentada pelo cartum? Qual será/seria o impacto nas ideias das pessoas acerca das interações entre ciência, tecnologia, sociedade e ambiente? Entre estes questionamentos, outros foram surgindo, como: Que ações de EA podem ser efetivadas em sala de aula com a análise dos cartuns? Que relações conceituais são apresentadas nos cartuns a serem abordadas no ensino? Neste sentido:

O que de um cartum pode ser lido, o quanto os temas controversos, em especial da EA trazem `s tona em sala de aula, algo que gostaríamos que vocês também refletissem visto a imposição do ponto de vista da mídia. A EA tem " $n$ " fatores que a mídia traz conduzindo as informações, o que precisa ser desmistificado mostrando para o aluno o quanto é importante fazer uma leitura crítica do que nos é apresentado diariamente (FORMADOR C). 
Além de a mídia dominar a tecnologia da informação (sabendo que não se aprende com o acúmulo de informações), o professor precisa saber conduzir a construção do conhecimento desmistificando o que nos é imposto principalmente pela mídia. Nesse sentido, Loureiro argumenta: "[...] a educação ambiental crítica é bastante complexa em seu entendimento de natureza, sociedade, ser humano e educação, exigindo amplo trânsito entre ciências (sociais ou naturais) e filosofia, dialogando e construindo pontes e saberes transdisciplinares" (2007, p. 69). A questão é perceber a necessidade de ir além do uso de jogos didáticos, de cartuns, filmes, entre outros, mesmo que também sejam importantes, exigindo-se mais reflexão, tempo/espaço para discussão das questões controversas em âmbito escolar.

A seguir destacamos uma das imagens de cartum que foi analisada por um dos grupos, bem como é expressa a opinião na fala de um dos licenciandos descrito a seguir.

Figura 1 - Imagem de um cartum analisado em aula

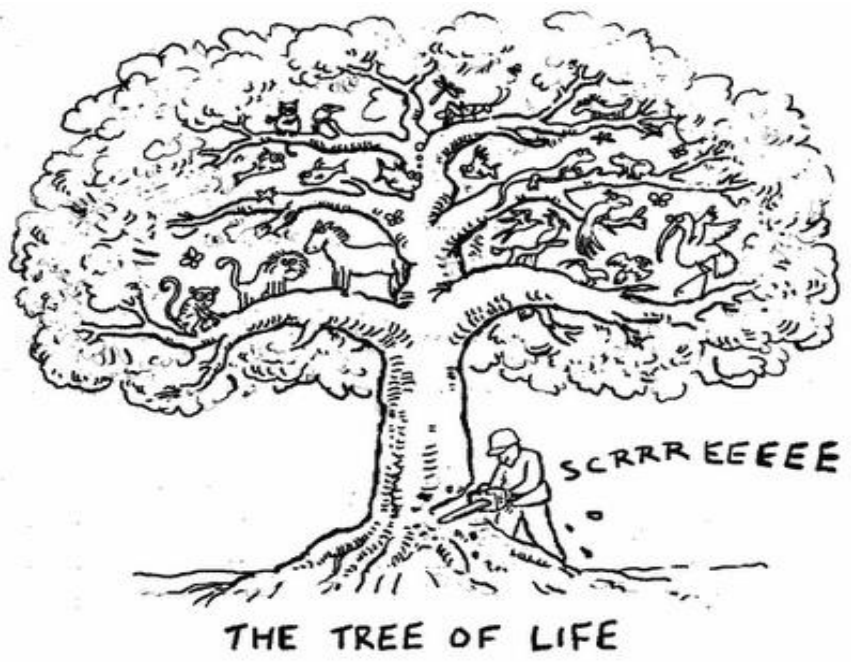

Fonte: http://jonathanandmelanie.blogspot.com.br/2011/05/tree-of-life-satirical-cartoon.html.

Aqui nas relações a gente viu que é a árvore da vida, o homem está destruindo a árvore, é uma visão antropocêntrica [...] aparentemente acha que não vai influenciar na sua vida, mesmo destruindo a vida de outros animais, outros seres, e não a dele. Ao cortar a árvore da vida está acabando com a própria vida, sem perceber os valores ambientais e morais em relação a não relacionar a teoria que todo mundo conhece com a prática de efetivamente não destruir a natureza. Temos que ir além, buscar a sensibilização para mudar ações humanas que demonstram um pensamento antropocêntrico. A sociedade ao fazer uso da ciência e da tecnologia interferindo no ambiente muitas vezes de forma negativa causa desequilíbrio ecológico, impactando no clima, são temas que precisam ser abordados a partir de um cartum sensibilizando em relação à preservação, discussão e reflexão, visto a exploração do meio ambiente, uso inapropriado dos recursos naturais (LICENCIANDO A).

Partindo do excerto supramencionado podemos observar que o grupo destacou a importância do cuidado das ações do homem com relação à natureza, pois as ações humanas podem trazer implicações positivas ou negativas ao próprio homem. Em relação à Figura 2, mais um dos cartuns que foi analisado, as ideias que foram discutidas no grupo também foram apresentadas ao grande grupo por um Licenciando (B). 
Figura 2 - Imagem de um cartum analisado em aula

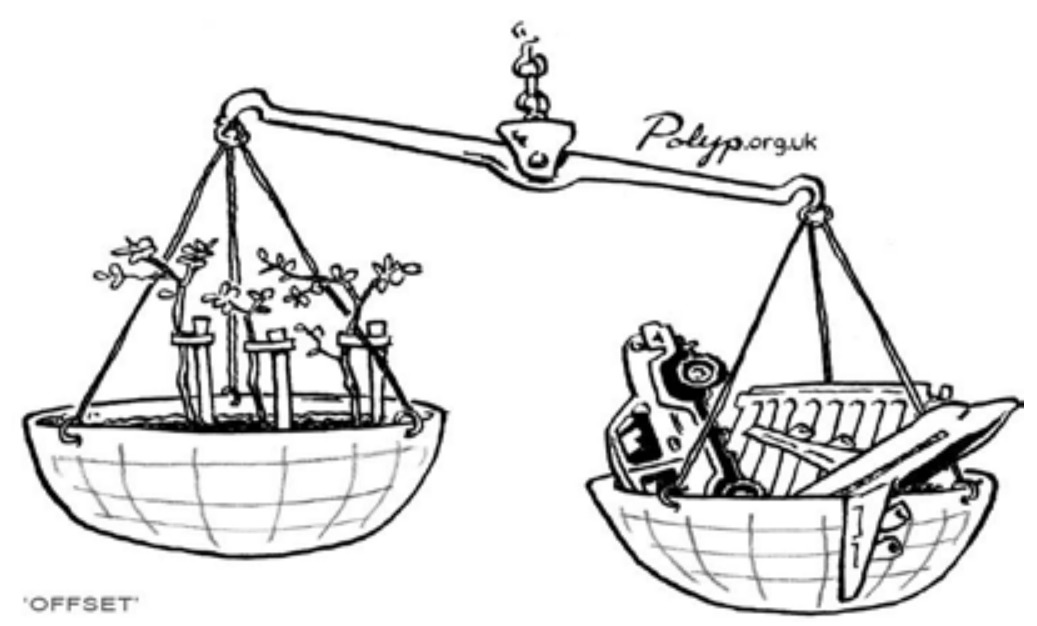

Fonte: https://www.google.com.br/search?q=catuns+polyp.org.uk\&client=firefo$x-b \& d c r=0 \&$ source $=I n m s \& t b m=i s c h \& s a=X \& v e d=0 a h U K E w i H 6 a e F r b n Z A h V H E Z A K H T 9 j D i w Q \_A U I C i g B \&$ biw $=1152 \&$ bih $=588 \# i m g r c=v u y U Q R X J S D N 2 V M$.

O nosso grupo pegou essa balança, nesta balança vários aspectos estão relacionados. $O$ primeiro é a poluição versus a natureza. Esta que se rejuvenesce olhando a balança mais leve, sabendo que o ser humano pensa mais no consumo olhando a balança mais pesada do que na preservação da natureza, lugar de que provêm os recursos da matéria-prima (LICENCIANDO B).

Por meio do excerto percebemos duas questões fundamentais ao discutimos sobre EA, ou seja, a poluição e a natureza se reconstituindo. É preciso abordar sobre os valores que o homem enfatiza, a começar pela desmistificação do consumismo. É necessário destacar o cuidado com as plantas, uma vez que as ações do homem podem influenciar nas consequências futuras, podendo ser positivas ou não, dependendo das ações do homem.

$\mathrm{Na}$ imagem podemos observar que as plantas são jovens, foram plantadas. Esse plantio de árvores se preservado a tempo e cuidado, em contrapartida ao consumo, quando as plantas crescerem esta balança pode entrar em equilíbrio ou até superar o consumo. Mas aí tem a parte do consumo consciente, os impactos, as ideias, o cuidado com o ambiente, os três erres (reduzir, reutilizar e reciclar). Algumas das muitas questões precisam ser abordadas em sala de aula no ensino de ciências na desmistificação do impacto ambiental com relação ao consumo. Questões divergentes como da imagem precisam ser trabalhadas sobre poluição, consumo, descarte de materiais, e assim por diante (LICENCIANDO B).

Percebemos pela declaração anterior os vários aspectos relacionados ao cartum observado, como questões referentes à preservação do meio ambiente, além do consumo induzido e o impacto que o homem causa ao ambiente.

O professor poderá sugerir temas numa sequência que vá do local ao global e vice-versa; do ambientalmente equilibrado, saudável, diversificado e desejável, ao degradado ou poluído, para que se sinta a necessidade de se superar essa situação; e indicar medidas necessárias, discutir responsabilidades, decidir possíveis contribui- 
ções pessoais e coletivas, [...] para tornar o ambiente cada vez melhor e os alunos cada vez mais comprometidos com a vida, a natureza, a melhoria dos ambientes com os quais convivem (BRASIL, 1997, p. 43).

Partindo das questões propostas pelos PCNs destacamos a importância da realização de um trabalho como este, que faz uso de cartuns. Conforme Tristão (2004, p. 29), "[...] as atividades humanas produzidas provocam um tremendo impacto no meio ambiente, porque são essencialmente dominadas pelo valor de troca e não por leis ecológicas ambientais", o que nos faz pensar na importância das ações do homem na relação com o ambiente.

É por meio das ações que podemos contribuir cada vez mais como profissionais da educação preocupados com as questões ambientais. Com o uso de cartum é possível realizar um trabalho de análise das ações do homem, por exemplo, ao refletir e compartilhar ideias de como está ou poderá ficar o meio ambiente, dependendo das ações do homem, entre diversas outras estratégias de ensino, para então ajudar os alunos a construírem o próprio conhecimento, criticando e confrontando diferentes valores. Nas ideias de Uhmann e Zanon (2012, p. 12),

[...] saberes experienciais poderão contribuir para o trabalho docente através das ações diferenciadas, quando socializados numa discussão coletiva entre professores em formação inicial (licenciandos) e continuada (professor formador e das escolas), que também estão preocupados com a melhoria do ensino e das questões socioambientais.

Ao abordar questões relacionadas aos cuidados ambientais em contexto escolar, em especial no ensino de Ciências, o docente contribui "[...] para a formação de cidadãos conscientes, aptos a decidir e atuar na realidade socioambiental de um modo comprometido com a vida, com o bem-estar de cada um e da sociedade, local e global" (BRASIL, 1998, p. 187), o que requer um trabalho coletivo entre os sujeitos escolares. Ou seja: "[...] o diálogo entre os professores é fundamental para consolidar saberes emergentes da prática profissional" (NÓVOA, 1992, p. 14), no que diz respeito ao nosso compromisso com as transformações sociais e as relações dinâmicas entre os seres vivos. Precisamos proporcionar condições para que os alunos sejam mais críticos, autônomos e capazes de ir construindo o conhecimento necessário a uma realidade complexa em permanente exploração dos recursos finitos de um ambiente que necessita ser preservado urgentemente.

\section{CONSIDERAÇÕES FINAIS}

Acreditamos que a formação continuada faz a diferença ao professor que precisa atualizar-se constantemente. Da mesma forma, o conhecimento das questões ambientais, um tema emergente e urgente, precisa ser proporcionado de forma reflexiva nos espaços de formação, o que proporcionará o desenvolvimento de diferentes atividades de EA possíveis de serem compartilhadas no ensino pedagógico e na utilização de metodologias adequadas ao cuidado ambiental nas escolas. 
Precisamos de mais iniciativas, ou seja, de sentimento de pertencimento sobre o espaço local-global para irmos conhecendo mais a realidade, assim ajudando nas decisões de cuidado ambiental, haja vista a ampliação de conhecimento sobre a cultura de desenvolvimento social, ambiental e ético. No que se refere "[...] à participação dos indivíduos na sociedade, torna-se evidente que, para o cidadão efetivar a sua participação comunitária, é necessário que ele disponha de informações" (SANTOS; SCHNETZLER, 2003, p. 47). Para tanto, um espaço de formação que possibilita aos docentes e licenciandos, novos conhecimentos, a exemplo da EA, prioriza momentos de compartiIhamento de experiências vivenciadas. Estas podem ser discutidas e melhoradas no momento de seu replanejamento, em virtude do que foi vivenciado no encontro realizado dos ciclos formativos em que licenciandos e docentes tiveram a oportunidade de aprender um pouco mais sobre a legislação, PCN do meio ambiente, assim como trocarem experiências. Enfim, tais experiências podem contribuir para que outros colegas também desenvolvam mais atividades referentes às questões socioambientais.

Pesquisar a própria prática pedagógica é aceitar os desafios que ela impõe buscando aprendizado permanente, de referência para os discentes e docentes no processo de construção do conhecimento. Destaca-se que a discussão dos conceitos em estudo quando articulados com questões controversas, a exemplo das relacionadas com a EA, contribuem com a escolarização dos alunos dentro e fora da sala de aula. Neste sentido, o uso de cartuns poderá proporcionar o levantamento de questões controversas entre os professores e alunos. Estes, em conjunto, analisam, refletem e socializam as ideias debatidas no pequeno e grande grupo, os quais podem ser desenvolvidos principalmente nas escolas no trabalho com as questões ambientais, entre outros temas educacionais.

Enfim, necessitamos de espaços para que grupos de professores em formação inicial e continuada tenham a possibilidade de interagir uns com os outros, discutindo sobre concepções e práticas pedagógicas desenvolvidas em sala de aula, assim como do encontro dos ciclos formativos em que os licenciandos em contato com os professores de diferentes escolas interagiram aprendendo com as experiências compartilhadas no grupo. Um espaço/tempo realizado sistematicamente (mensalmente), de fundamental importância para a articulação das ideias, concepções e práticas, momento de reflexão para a pesquisa, ensino e extensão num processo permanente, constituindo-se como uma das maneiras de aprimorarmos conhecimentos do ser docente diante do urgente ensino da EA.

\section{REFERÊNCIAS}

BRASIL. Parâmetros Curriculares Nacionais: terceiro e quarto ciclos do Ensino Fundamental; temas transversais. Secretaria da Educação Fundamental. Brasília: MEC; SEF, 1998. Disponível em: http://portal.mec. gov.br/seb/arquivos/pdf/ttransversais.pdf. Acesso em: 18 out. 2017.

BRASIL. Diretrizes Curriculares Nacionais de Educação Ambiental pelo Conselho Nacional de Educação. 2000. Disponível em: http://conferenciainfanto.mec.gov.br/images/conteudo/iv-cnijma/diretrizes.pdf Acesso em: 9 set. 2018.

BRASIL. Parâmetros Curriculares Nacionais: meio ambiente e saúde. Secretaria de Educação Fundamental. Brasília: MEC; SEF, 1997. Disponível em: http://portal.mec.gov.br/seb/arquivos/pdf/meioambiente. pdf. Acesso em: 18 nov. 2017. 
BRASIL. Política Nacional de Educação Ambiental, $n^{\circ} 9.795$ de 27 de abril de 1999. 1999. Disponível em: http://www.planalto.gov.br/ccivil_03/leis/19795.htm. Acesso em: 4 fev. 2018.

CAVALCANTI, Júlia Nazário de Abreu. Educação ambiental: conceitos, legislação, decretos e resoluções pertinentes e a formação continuada de professores em educação ambiental na Paraíba. Revista Eletrônica de Mestrado em Educação Ambiental (Remea), v. 30, n. 1, p. 71-82, jan./jun. 2013. Disponível em: https://www.seer.furg.br/remea/article/view/3723. Acesso em: 5 jan. 2018.

CONFERÊNCIA DE TBILISI. Algumas recomendações da Conferência Intergovernamental sobre Educação Ambiental aos Países Membros. 1977. Disponível em: http://www.fzb.rs.gov.br/upload/ 20130508155354 tbilisi.pdf. Acesso em: 5 jan. 2018.

DECLARAÇÃO DE ESTOCOLMO. Declaração sobre Direitos humanos. 1972. Disponível em: http://portal. iphan.gov.br/uploads/ckfinder/arquivos/Declaracao\%20de\%20Estocolmo\%201972.pdf. Acesso em: 21 dez. 2017.

GÜLLICH, Roque Ismael da Costa. Didática das ciências. 1. ed. Curitiba: Appris, 2013.

JACOBI, Pedro. Educação ambiental, cidadania e sustentabilidade. Cadernos de Pesquisa, n. 118, p. 189205, mar. 2003. Disponível em: http://www.scielo.br/pdf/cp/n118/16834.pdf. Acesso em: 1 fev. 2018.

LIBÂNEO, José Carlos. Didática. São Paulo: Cortez, 1994.

LOUREIRO, Carlos Frederico Bernardo. Trajetória e fundamentos da educação ambiental. 2. ed. São Paulo: Cortez, 2006.

LOUREIRO, Carlos Frederico B. Educação ambiental crítica nas escolas: desafios. In: MELLO, Soraia Silva de; TRAJBER, Rachel. Vamos cuidar do Brasil: conceitos e práticas em educação ambiental na escola. Brasília: Ministério da Educação; Coordenação Geral de Educação Ambiental; Ministério do Meio Ambiente; Departamento de Educação Ambiental; Unesco, 2007. p. 66-72.

LÜDKE, Menga; ANDRÉ, Marli. Pesquisa em educação: abordagens qualitativas. São Paulo: EPU, 2011.

NÓVOA, António. Formação de professores e profissão docente. Repositório da Universidade de Lisboa. 1992. Disponível em: http://hdl.handle.net/10451/4758. Acesso em: 13 jan. 2018.

REIS, Pedro Rocha dos. Os temas controversos na educação ambiental. Pesquisa em Educação Ambiental, vol. 2, n. 1, 2007, p. 125-140 Disponível em: http://www.revistas.usp.br/pea/article/view/30021/31908. Acesso em: 13 fev. 2018.

SANTOS, Wildson Luiz Pereira dos; SCHNETZLER, Roseli Pacheco. Educação em Química: compromisso com a cidadania. 3. ed. ljuí: Ed. Unijuí, 2003.

SCHULZ, Marcia Seidenfuz et al. Educação ambiental na educação básica e superior segundo licenciandos de ciências biológicas e professores em exercício. Revista Eletrônica de Mestrado em Educação Ambiental (Remea), v. 29, jul./dez. 2012. Disponível em: https://www.seer.furg.br/remea/article/view/2956. Acesso em: 5 jan. 2018.

TRISTÃO, Martha. A educação ambiental na formação de professores: redes de saberes. São Paulo: Annablume, 2004.

UHMANN, Rosangela Ines Matos; ZANON, Lenir Basso. Ações pedagógicas no ensino de física com foco na educação ambiental. Revista Eletrônica de Mestrado em Educação Ambiental (Remea), v. 29, jul./dez. 2012. Disponível em: https://www.seer.furg.br/remea/article/view/2944. Acesso em: 5 jan. 2018.

UHMANN, Rosangela Ines Matos. Estratégias de ensino e interações em aulas de física e Química no Ensino Médio com foco na educação ambiental. 2011. Dissertação (Mestrado) - Universidade Regional do Noroeste do Estado do Rio Grande do Sul, Unijuí, Programa de Pós-Graduação em Educação, 2011. Disponível em: http://bibliodigital.unijui.edu.br:8080/xmlui/handle/123456789/285. Acesso em: 5 fev. 2018. 